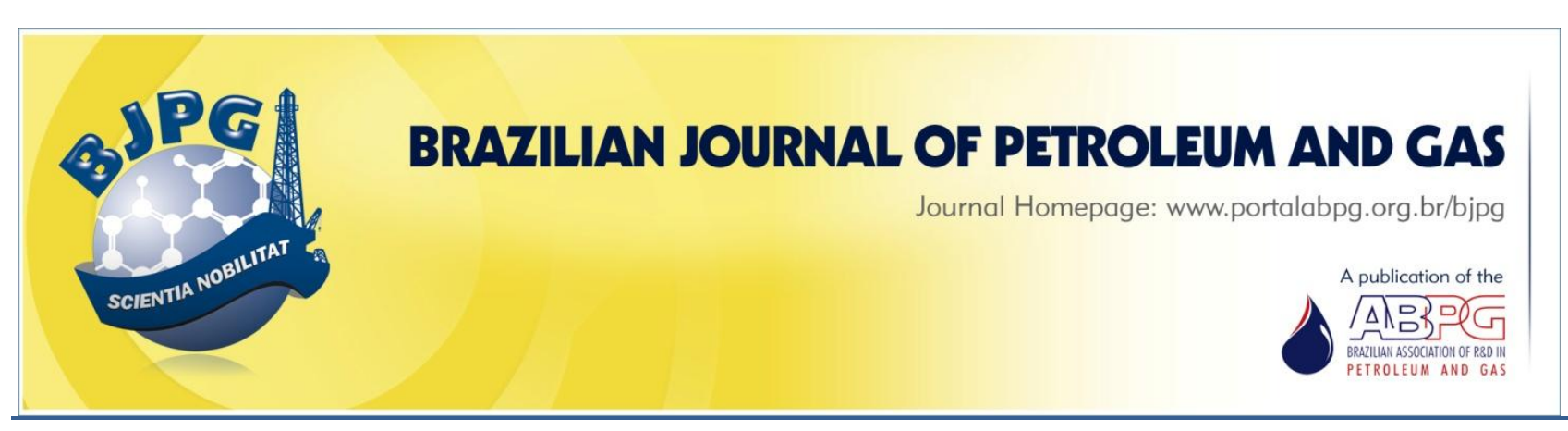

\title{
PRESSURE DROP IN TOOL JOINTS FOR THE FLOW OF WATER-BASED MUDS IN OIL WELL DRILLING
}

\author{
${ }^{\text {a }}$ Calçada, L. A. ${ }^{1}$; ${ }^{\text {Eler, F. M.; }}{ }^{\text {a }}$ Paraiso, E. C. H.; ${ }^{\text {Scheid, C. M.; }}{ }^{\text {}}$ Rocha, D. C.
}

\footnotetext{
${ }^{a}$ Federal Rural University of Rio de Janeiro, Department of Chemical Engineering, Rio de Janeiro, Brazil
}

${ }^{b}$ PETROBRAS S.A./CENPES/PDP/TEP, Rio de Janeiro, Brazil

\begin{abstract}
The characteristics of the fluid flows in tool joints were studied experimentally and theoretically in a laboratory scale. The goal of this study was to evaluate the pressure drop in accessories such as tool joints, placed along the drilling columns. The experimental fluid flow loop consisted of a 25 -hp positive displacement pump, a 500-liter tank, a 3-HP mixer and a series of circular and annular pipes where the tool joints were installed. Based on the Reynolds number, the fluid flow loop was set to have dynamic similarity with respect to the real hydraulics of oil well fields. CFD simulations were implemented to aid in the design of the fluid flow loop. Pressure drop and fluid flow rate data were experimentally determined in a set of tool joints using water-based muds with non-Newtonian behavior. The CFD simulations showed a good performance on the tool joint simulations. Finally, the literature's correlations originally employed by Petrobras were used to estimate the friction factor, and new parameters for these correlations were established. The evaluation of the parameters improved the predictive capacity mostly in the laminar regime.
\end{abstract}

\section{KEYWORDS}

pressure drop; oil well design; friction factor

\footnotetext{
${ }^{1}$ To whom all correspondence should be addressed.

Address: Department of Chemical Engineering, Federal Rural University of Rio de Janeiro, BR465, km7, Seropédica, Rio de Janeiro- Brazil - CEP 23890-000

Telephone / Fax: +55 21 3787-8742 / +55 21 3787-3750 | E-mail: calcada@ufrri.br doi:10.5419/bjpg2012-0012
} 


\section{INTRODUCTION}

During drilling operations, fluids are used to clean the wellbore, to keep the borehole open until the cementing stage, to exert hydrostatic pressure, and to cool and lubricate the bit and the drill string. Most of these drilling fluids have non-Newtonian behavior (Bourgoyne et al., 1991).

The calculation of pressure drop during the flow through drilling accessories, such as circular and annular pipes, is highly important in the design and control of the drilling operation. Among the accessories, tool joints are highlighted. Tool joints are the enlarged and threaded ends of drill pipes, which provide great strength and high pressure. These connections are sufficiently robust to survive the rigors of drilling and numerous cycles of tightening and loosening at threads.

There are several correlations in the literature to calculate the pressure drops in tool joints. The CFD packages are another alternative for these calculations. The application of these packages has grown in research works and in the industry, becoming an important tool in the investigation of fluid dynamics. CFD allows the modeling of complex physical systems, which usually do not have analytical solutions.

This work validates the literature's correlation used to calculate the friction factor for tool joints. To simulate the tool joints, a fluid flow loop was built in order to obtain experimental data of pressure drop in the tool joints as a function of the volumetric flow rate. The experimental data allowed the determination of pressure drop coefficients. Literature parameters for some of the correlations were evaluated. These evaluations improved the predictive capacity of calculating the friction factor for real drilling fluids applications for the set of tool joint studied. For parameter evaluation, a code based on the maximum likelihood principle was written.

\section{PRESSURE DROP IN TOOL JOINTS}

Simões (2005) used CFD techniques to simulate the flow of water and polymer solutions with nonNewtonian behavior in tool joints in real dimensions, and proposed correlations of pressure drop using simulated data.

The literature presents a simplified treatment for the geometry of tool joints, dividing them into three distinct regions: an abrupt contraction, a straight section, and an abrupt expansion (see Figure 1). This simplification was used by Jeong and Shah (2004) to develop correlations of pressure drop for the external flow over the tool joints, and by McCain (1994) to obtain correlations for internal flow in the tool joints. Mendes et al. (2007) studied the flow of viscoplastic fluids through axisymmetric contractions followed by expansions.

For the straight region, the loss for internal flow in circular pipes and external flow in annular region is calculated by Equation 1 .

$$
\frac{\Delta \mathrm{P}}{\rho}=4 \mathrm{f}\left(\frac{\mathrm{L}}{\mathrm{D}}\right) \frac{\mathrm{v}^{2}}{2}
$$

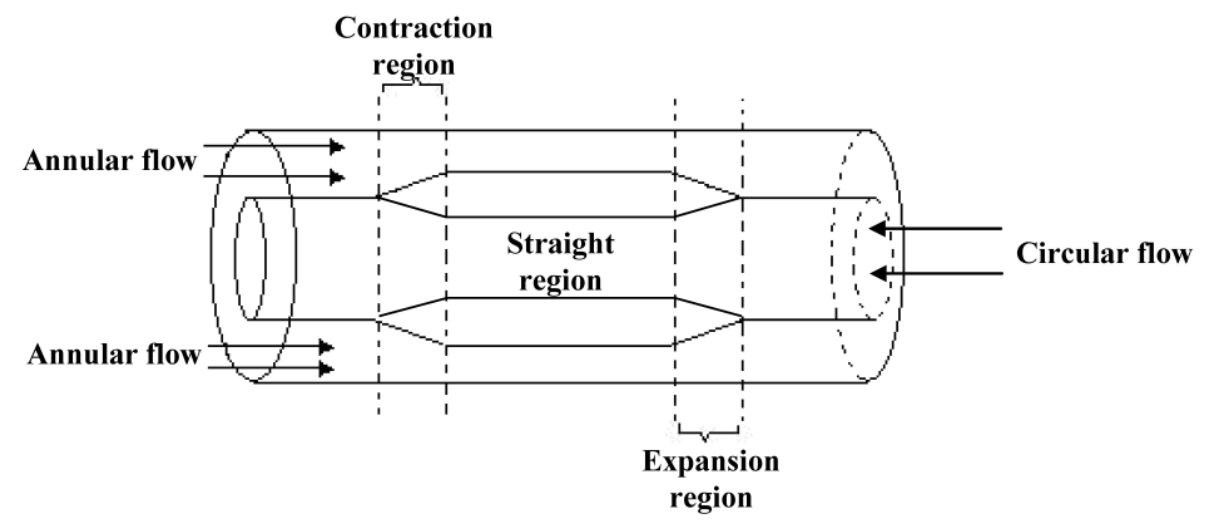

Figure 1. Schematic of a tool joint divided into three distinct regions: contraction, expansion and straight section. 
Where $f$ is the Fanning friction factor (dimensionless), $L$ is the length of the straight region $(m), D$ is the diameter of the circular pipe $(m)$, or the hydraulic diameter $(m)$, and $v$ is the fluid velocity $(\mathrm{m} / \mathrm{s})$.

To measure the pressure drop in accidents, it is necessary to position the measure points at a certain distance from the inlet and the outlet of the system. This is a precaution to avoid disturbances at the edges. In such cases, additional pressure drop caused by this distance should be calculated by Equation 1 and subtracted from the results.

In laminar flow regime, the friction factor $f$ can be calculated by Equation 2 (Fox et al., 2004):

$$
\mathrm{f}=\frac{16}{\operatorname{Re}}
$$

Where $\mathrm{Re}$ is the Reynolds number for the generalized power-law model (dimensionless). To calculate the friction factor in turbulent flow, Scheid et al. (2011) validated Equations 3 and 4, proposed by Gomez (1987), both useful for waterbased muds.

$$
\begin{aligned}
& f=0.069 n^{0.666} \operatorname{Re}^{-0.235} \\
& f=0.110 n^{0.616} \operatorname{Re}^{-0.287}
\end{aligned}
$$

For Equations 2, 3 and 4, the modified Reynolds number can be calculated by the Metzner and Reed (1955) model:

$$
\operatorname{Re}=\frac{D v \rho}{k\left(\frac{8 v}{D}\right)^{n-1}\left(\frac{3 n+1}{4 n}\right)^{n}}
$$

Where $D$ is the diameter of the circular pipe $(m)$ or the hydraulic diameter $(\mathrm{m})$ for annular pipes, $v$ is the fluid velocity $(\mathrm{m} / \mathrm{s}), \rho$ is the fluid density $\left(\mathrm{kg} / \mathrm{m}^{3}\right), \mathrm{k}$ and $\mathrm{n}$ are the rheological parameters of the power-law model. The hydraulic diameter can be defined by Equation 6 (Bourgoyne et al., 1991), which was developed considering the annular region as a gap between parallel flat plates:

$$
\mathrm{D}_{\mathrm{H}}=0.816\left(\mathrm{D}_{2}-\mathrm{D}_{1}\right)
$$

Where $D_{1}$ and $D_{2}$ are respectively the internal and external diameters of pipes that form the annulus $(m)$. The velocity in the annular region can be calculated by Equation 7, where $Q$ is the flow rate $\left(\mathrm{m}^{3} / \mathrm{s}\right)$

$\mathrm{v}=\frac{4 \mathrm{Q}}{\pi\left(\mathrm{D}_{2}^{2}-\mathrm{D}_{1}^{2}\right)}$

Usually, correlations for calculation of friction factor in tool joints are divided in two groups: external flow correlations and internal flow correlations.

\subsection{Correlation for external flow}

Jeong and Shah (2004) performed pressure drop tests using non-Newtonian fluids for external flow in tool joints (annular region). The authors proposed a theoretical formulation for calculating the pressure drop in the contraction and expansion regions. The pressure drop in the section of straight region was calculated by Equation 1 . The loss of mechanical energy can be expressed by applying the Bernoulli equation at two points. Thus, the loss in a sudden expansion ( $\mathrm{Fe})$ and the loss in a rising contraction $(\mathrm{Fc})$ can be calculated by Equations 8 and 9, respectively (Fox et al., 2004):

$$
\mathrm{Fe}=\mathrm{Ke} \frac{\mathrm{V}_{1}^{2}}{2}
$$

$$
\mathrm{Fc}=\mathrm{Kc} \frac{\mathrm{V}_{1}^{2}}{2}
$$

Where $V_{1}$ is the average velocity of the fluid in the annular section with a smaller area; Ke and Kc are the coefficients of pressure drop in the expansion and contraction, respectively. The coefficients Kc and $\mathrm{Ke}$ are given by Equations 10 and 11, respectively.

$$
\mathrm{Kc}=0.5 \sqrt{\operatorname{sen} \frac{\theta \mathrm{c}}{2}\left(1-\beta^{2}\right)}
$$

$$
\mathrm{Ke}=\mathrm{B}\left(1-\beta^{2}\right)^{2}
$$

In Equation 10, $\theta \mathrm{c}$ is the angle of the region of contraction (degrees) and $\beta$ is the ratio between the internal and external diameters of the pipes (dimensionless). The constant B in Equation 11 can be taken as 1.0. Combining the equation of motion with the Bernoulli equation, the pressure drop 
$\left(\Delta \mathrm{P}_{\mathrm{c}, \mathrm{e}}\right)$ is then calculated by multiplying the density of the fluid by the loss of mechanical energy in the contraction or expansion region, as shown in Equation 12.

$$
\Delta \mathrm{P}_{\mathrm{c}, \mathrm{e}}=\mathrm{F}_{\mathrm{c}, \mathrm{e}} \rho
$$

\subsection{Correlation for internal flow}

McCain (1994) used some models to calculate the pressure drop for the internal flow in tool joints. For the contraction region, one has:

$$
\Delta \mathrm{P}_{\mathrm{c}}=\mathrm{AK}_{1} \frac{\rho \mathrm{Q}^{2}}{\left(\mathrm{D}_{\mathrm{I}}^{\mathrm{TJ}}\right)^{4}}
$$

Where $A=0.8710, D_{I}^{T J}$ is the tool joint inner diameter $(m)$ and $K_{1}$ is given by Equation 14 :

$$
\mathrm{K}_{1}=0.1508 \mathrm{x}_{\mathrm{c}}^{2}+0.0341 \mathrm{x}_{\mathrm{c}}
$$

Where $x_{c}$ can be calculated by Equation 15, with $D_{I}^{P}$ being the pipe inner diameter $(m)$ and $L_{c}$ the size of the contraction $(\mathrm{m})$.

$$
\mathrm{x}_{\mathrm{c}}=\frac{\mathrm{D}_{\mathrm{I}}^{\mathrm{P}}-\mathrm{D}_{\mathrm{I}}^{\mathrm{TJ}}}{2 \mathrm{~L}_{\mathrm{c}}}
$$

The model given by Equations $13-15$ is valid only if $x_{c} \leq 0.57$. When $x_{c}>0.57$, one can adopt $\mathrm{K}_{1}=0.07$.

For the expansion region, one has:

$$
\Delta \mathrm{P}_{\mathrm{e}}=\mathrm{AK}_{2} \frac{\rho \mathrm{Q}^{2}}{\left(\mathrm{D}_{\mathrm{I}}^{\mathrm{TJ}}\right)^{4}}
$$

Where $K_{2}$ is given by Equation 17, if $x_{e} \leq 0.8$ :

$$
\begin{aligned}
& \mathrm{K}_{2}=52.0648 \mathrm{x}_{\mathrm{e}}^{6}-165.2404 \mathrm{x}_{\mathrm{e}}^{5}+214.2392 \mathrm{x}_{\mathrm{e}}^{4}- \\
& -140.7675 \mathrm{x}_{\mathrm{e}}^{3}+44.4707 \mathrm{x}_{\mathrm{e}}{ }^{2}-3.4526 \mathrm{x}_{\mathrm{e}}+0.2188
\end{aligned}
$$

In this case, $x_{\mathrm{e}}$ can be calculated by Equation 18, where $L_{e}$ is the length of the expansion region.

$$
x_{e}=\frac{D_{I}^{P}-D_{I}^{T J}}{2 L_{e}}
$$

When $x_{e}>0.8$, one can adopt $K_{2}=1.1$.

\section{MATERIALS AND METHODS}

The experimental data of pressure drop and fluid flow rate of drilling fluids in tool joints were obtained in a flow loop. To protect trade secrets, the fluid samples were named BAC, BAS and BACAT. All of them were water-based fluids with additives. These fluids were provided by the Research Center of Petrobras (CENPES). These water-based drilling fluids had non-Newtonian behavior and were composed essentially of water, polymer solutions and solids in suspension. The fluid flow loop was designed to have the same Reynolds number with dynamic similarity usually applied in hydraulic design of oil wells.

\subsection{Fluid flow loop}

The loop was designed to maintain geometric and dynamic similarity with respect to the drilling systems of real fields. The fluid flow loop consisted of galvanized iron pipes, 6 meters long, arranged in seven independent lines (see Figure 2). The loop system was connected to a 500-L mix tank equipped with a 3-HP vertical mixer (1). The pumping of the drill fluid was achieved by a $25-\mathrm{HP}$ helical positive displacement pump (2). To control the fluid flow, a bypass (3) was used. To simulate the abrupt contraction and expansion geometries of the tool joints, annular lines composed of $1 \frac{1}{4}$-in and $1 / 2$-in diameter pipes $(4,6,8$ and 9$)$, and 2 -in and $3 / 4$-in diameter pipes (5) were used. A line (10) with different diameters ( 1 in, 2 in, $1 / 2$ in and $3 / 4$ in) was used to validate the friction factor in circular pipes. Three pressure gauges operating of different ranges $0.93-37 \mathrm{mmHg}, 3.12-373 \mathrm{mmHg}$ and $8.33-$ $1866 \mathrm{mmHg}$ were used to measure the pressure drop. These transducers (gauges) have enabled the study of a wide range of flow regimes. The flow rate was determined by a gravimetric technique, with triplicates of each point. The rheological data were obtained using a viscometer Fann 35A from fluid samples collected during the test at the same temperature of the tests. 


\section{1}

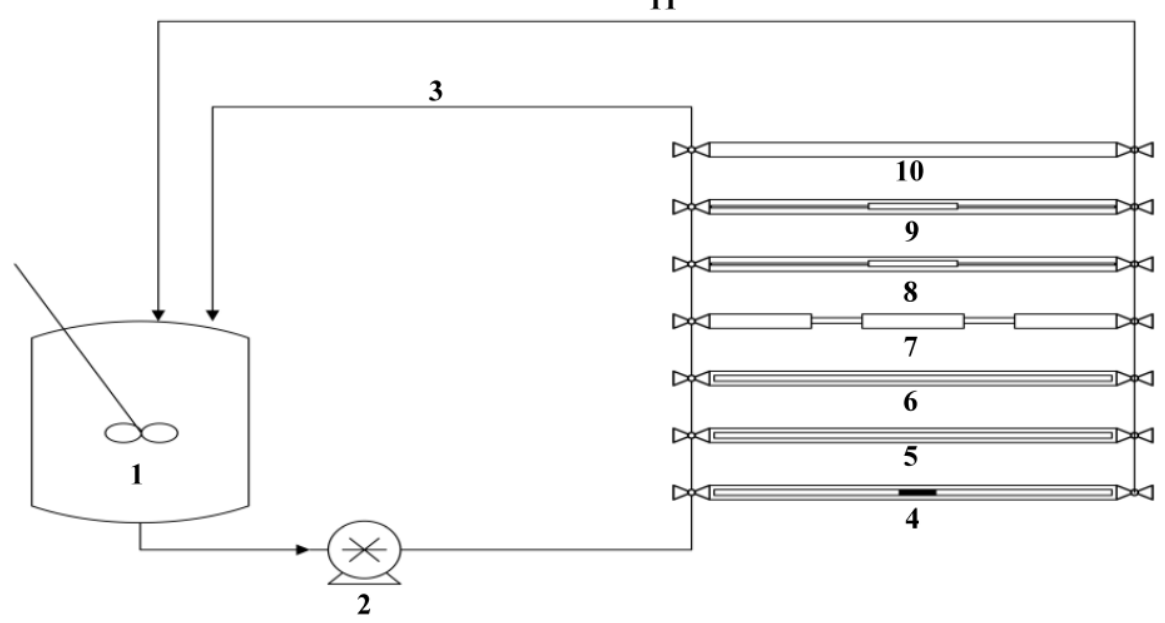

Figure 2. Scheme of the fluid flow loop.

Tool joints in two flow configurations (internal and external flow) were studied separating the influence of these flows with respect to expansions, contractions and straight sections. The dimensions of the tool joints were calculated based on the work of Simões (2005), as shown in Figures $3 a$ and $3 b$.

For external flow, the geometry of the prototype was shown in Figure $3 a$. The angles were equal to $18^{\circ}$ for the input and $35^{\circ}$ for the output, or both equal to $90^{\circ}$. For internal flow, the geometry of the prototype was shown in Figure $3 \mathrm{~b}$. The diameters of the parts were $15.24 \mathrm{~mm}$ and 19.56 $\mathrm{mm}$, the angles were $18^{\circ}$ for input and $35^{\circ}$ for output in both parts. The experimental data were obtained in triplicate.

\subsection{Experimental \\ evaluation \\ of uncertainties}

In this study, all data were collected in triplicate and the propagation of uncertainties of the experimental data on the variables was calculated. The analysis of the uncertainties involves the calculation of the associated error inherent in all measurements (Himmelblau, 1970). The coverage factor was adopted equal to 2 for the calculation of uncertainty, given by $2 \sigma_{i}$, and the confidence level of $95 \%$ was chosen. The propagation of errors in calculating an interest variable $Y$, calculated from experimental data of $X$ and $Z$ which present the uncertainties $\sigma_{x}$ e $\sigma_{z}$ respectively, is calculated by Equation 19.

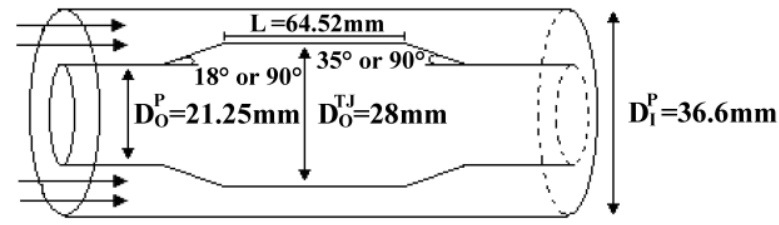

(a)

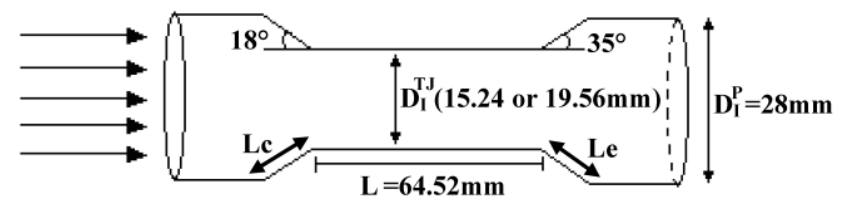

(b)

Figure 3. Accident's schematic representing: (a) the external tool joint flow and (b) the internal tool joint flow. 


$$
\sigma_{y}^{2}=\left(\frac{\partial y}{\partial x}\right)^{2} \sigma_{x}^{2}+\left(\frac{\partial y}{\partial z}\right)^{2} \sigma_{z}^{2}+\left(\frac{\partial y}{\partial x}\right)\left(\frac{\partial y}{\partial z}\right) \sigma_{x} \sigma_{z}
$$

The third term, $\sigma_{x} \sigma_{z}$, is considered when determining a given trial, which is influenced by other terms. In the calculations involved in this work, this term was not considered.

\subsection{Conservation equations for CFD simulation}

In this work, commercial CFD packages GAMBIT ${ }^{\oplus}$ and FLUENT $^{\oplus}$ was used to obtain pressure and velocity profiles in both internal and external flow. The analysis of the velocity profile was important to determine the positioning of the pressure measurement points in the experimental setup. Analysis of pressure profile, obtained through CFD simulation, together with the experimental data, was useful in the evaluation of the correlations of pressure drop. The same dimensions of Figures 3a and $3 \mathrm{~b}$ were adopted to construct tridimensional meshes in GAMBIT ${ }^{\oplus}$. Besides the dimensions of the tool joints, 0.8-m circular or annular sections on the input and output were added. These sections were taken into account in order to achieve the fully developed flow regime. Figures 4 and 5 illustrate the geometries used for the tool joint's external and internal flow, respectively.

In this work, the isothermal and incompressible approaches are reasonable, insofar as the authors worked at ambient temperatures and the fluids were made of water. In drilling operations the flow regimes is often laminar or transition. The experiments were carried out in the laminar regime and permanent flow. Then, the conservation equations were simplified in this way, by assuming isothermal, laminar, incompressible and permanent flow.

Thus, the continuity equation reduces to:

$\frac{1}{\mathrm{r}} \frac{\partial}{\partial \mathrm{r}}\left(\mathrm{rv}_{\mathrm{r}}\right)+\frac{1}{\mathrm{r}} \frac{\partial}{\partial \theta}\left(\mathrm{v}_{\theta}\right)+\frac{\partial}{\partial \mathrm{z}}\left(\mathrm{v}_{\mathrm{z}}\right)=0$

Components $r, \theta$, and $z$ in the equation of motion assume the form:

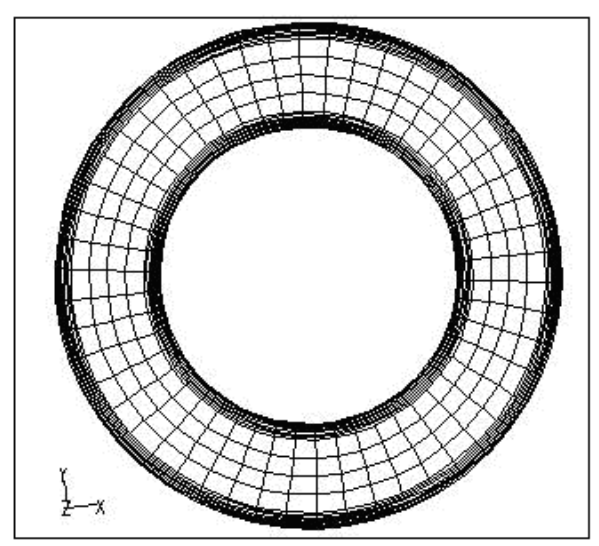

Figure 4. Cross section of the tool joint with external flow $\left(\theta c=18^{\circ} / \theta e=35^{\circ}\right)$.

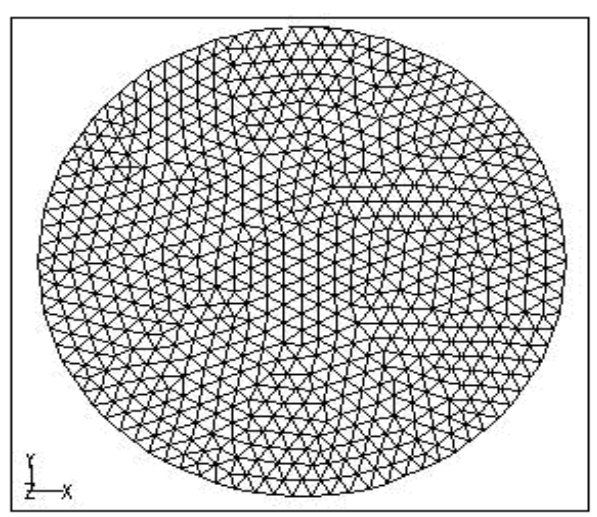

Figure 5. Cross section of the tool joint with internal flow $\left(D_{I}^{T J}=0.1524 \mathrm{~m}\right)$.

$$
\begin{aligned}
& \rho\left(\mathrm{v}_{\mathrm{r}} \frac{\partial \mathrm{v}_{\mathrm{r}}}{\partial \mathrm{r}}+\frac{\mathrm{v}_{\theta}}{\mathrm{r}} \frac{\partial \mathrm{v}_{\mathrm{r}}}{\partial \theta}+\mathrm{v}_{\mathrm{z}} \frac{\partial \mathrm{v}_{\mathrm{r}}}{\partial \mathrm{z}}-\frac{\mathrm{v}_{\theta}^{2}}{\mathrm{r}}\right)= \\
& =-\frac{\partial \mathrm{P}}{\partial \mathrm{r}}-\left(\frac{1}{\mathrm{r}} \frac{\partial}{\partial \mathrm{r}}\left(\mathrm{r} \tau_{\mathrm{rr}}\right)+\frac{1}{\mathrm{r}} \frac{\partial \tau_{\theta \mathrm{r}}}{\partial \theta}+\frac{\partial \tau_{\mathrm{zr}}}{\partial \mathrm{z}}-\frac{\tau_{\theta \theta}}{\mathrm{r}}\right)+\rho \mathrm{g}_{\mathrm{r}}
\end{aligned}
$$

$\rho\left(\mathrm{v}_{\mathrm{r}} \frac{\partial \mathrm{v}_{\theta}}{\partial \mathrm{r}}+\frac{\mathrm{v}_{\theta}}{\mathrm{r}} \frac{\partial \mathrm{v}_{\theta}}{\partial \theta}+\mathrm{v}_{\mathrm{z}} \frac{\partial \mathrm{v}_{\theta}}{\partial \mathrm{z}}+\frac{\mathrm{v}_{\mathrm{r}} \mathrm{v}_{\theta}}{\mathrm{r}}\right)=$

$=-\frac{1}{\mathrm{r}} \frac{\partial \mathrm{P}}{\partial \theta}-\left(\frac{1}{\mathrm{r}^{2}} \frac{\partial}{\partial \mathrm{r}}\left(\mathrm{r}^{2} \tau_{\mathrm{r} \theta}\right)+\frac{1}{\mathrm{r}} \frac{\partial \tau_{\theta \theta}}{\partial \theta}+\frac{\partial \tau_{\mathrm{z} \theta}}{\partial \mathrm{z}}+\frac{\tau_{\theta \mathrm{r}}-\tau_{\mathrm{r} \theta}}{\mathrm{r}}\right)+\rho \mathrm{g}_{\theta}$

$\rho\left(\mathrm{v}_{\mathrm{r}} \frac{\partial \mathrm{v}_{\mathrm{z}}}{\partial \mathrm{r}}+\frac{\mathrm{v}_{\theta}}{\mathrm{r}} \frac{\partial \mathrm{v}_{\mathrm{z}}}{\partial \theta}+\mathrm{v}_{\mathrm{z}} \frac{\partial \mathrm{v}_{\mathrm{z}}}{\partial \mathrm{z}}\right)=$

$=-\frac{\partial \mathrm{P}}{\partial \mathrm{z}}-\left(\frac{1}{\mathrm{r}} \frac{\partial}{\partial \mathrm{r}}\left(\mathrm{r} \tau_{\mathrm{rz}}\right)+\frac{1}{\mathrm{r}} \frac{\partial \tau_{\theta \mathrm{z}}}{\partial \theta}+\frac{\partial \tau_{\mathrm{zz}}}{\partial \mathrm{z}}\right)+\rho \mathrm{g}_{\mathrm{z}}$ 
For non-Newtonian fluids, the stress tensor $\tau$ is a function of the effective viscosity $\mu(\lambda)$, as shown in Equation 24:

$$
\tau=\mu(\lambda) \lambda
$$

\section{RESULTS AND DISCUSSION}

The values of specific gravities of fluids BAC, BAS, and BACAT were obtained by gravimetric tests, having obtained the values of $1.066 ; 1.150$ and $1.133 \mathrm{~kg} / \mathrm{m}^{3}$, respectively. The rheology data were obtained in a FANN viscometer, model 35A, and the power-law rheological model was used, represented by Equation 25, Bird et al. (2002).

$\tau=\mathrm{k} \lambda^{\mathrm{n}}$

Where $\tau$ is the shear stress, $\lambda$ is the shear rate, $k$ and $\mathrm{n}$ are the fluid consistency and fluid behavior index, respectively. Table 1 shows the rheological parameters and the correlation coefficients for all fluids studied. Power Law behavior index $\mathrm{n}$ and consistency index $\mathrm{k}$ were determined for all fluids from the linear regression of log shear stress versus log shear rate plots derived from Fann 35A data.

\subsection{CFD Simulations}

The CFD simulations helped the fluid flow loop design defining the best positions to place the pressure measurement devices. The pressure
Table 1. Mean values of rheological parameters for fluids BAC, BAS and BACAT with $25 \leq \mathrm{T} \leq 40^{\circ} \mathrm{C}$.

\begin{tabular}{cccc}
\hline Fluid & $\mathrm{k} \pm 2 \sigma_{\mathrm{k}}$ & $\mathrm{n} \pm 2 \sigma_{\mathrm{n}}$ & $\mathrm{R}^{2}$ \\
\hline BAC & $1.1 \pm 0.1$ & $0.46 \pm 0.01$ & 0.99 \\
BAS & $3.8 \pm 0.2$ & $0.26 \pm 0.01$ & 0.99 \\
BACAT & $5.4 \pm 0.7$ & $0.24 \pm 0.02$ & 0.99 \\
\hline \multicolumn{4}{l}{$2 \sigma$ is the uncertainty of the parameter obtained. }
\end{tabular}

measurement points had to be conveniently located to ensure a fully developed flow, i.e., no disturbances could be caused by the edges of the pipes. Based on CFD simulations, the pressure drop measurements were taken at a distance of 0.5 meter before and after each accident. This distance was sufficient to condition the drill fluid to flow properly in order to achieve the full profile for all abrupt contraction and expansion regions.

As results of the CFD simulation for fluid flow, Figures 6 and 7 show typical profiles of velocity and pressure obtained in the laminar flow. For both internal and external configurations of tools joint, the behavior was qualitatively the same. Figure 6 shows the pressure drop in an external flow configuration. There is a sudden drop in pressure caused by the flow accessory.

Figure 7 shows that the velocity of the fluid undergoes light oscillations in the straight section regions preceding and succeeding the tool joints.

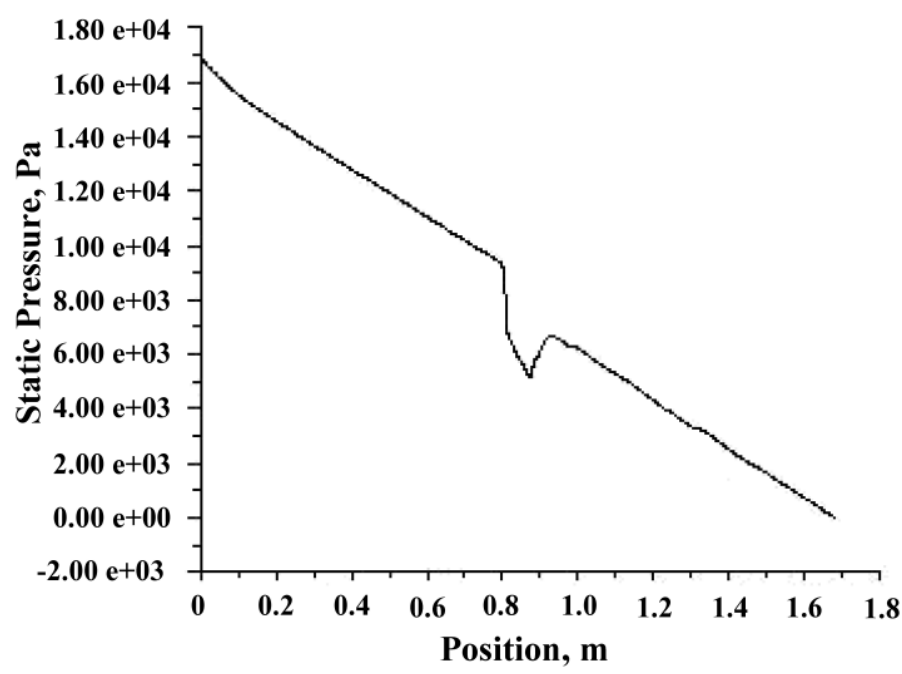

Figure 6. Pressure profile along the pipe, with flow external to the tool joint; $\theta \mathrm{c}=18^{\circ} / \theta \mathrm{e}=35^{\circ}$; BACAT fluid. 


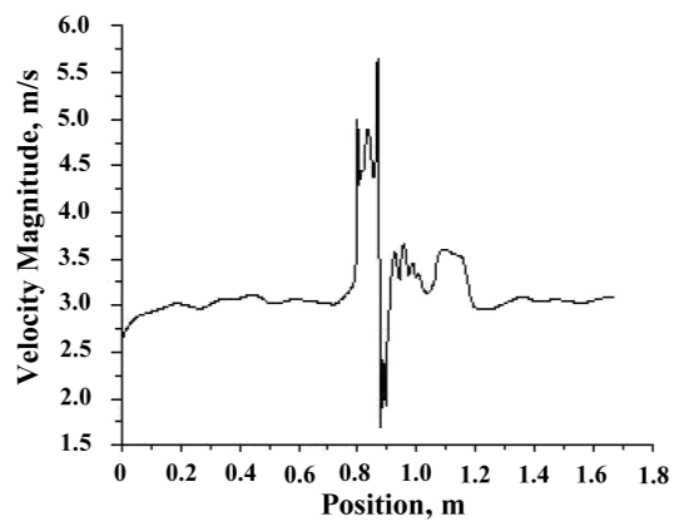

Figure 7. Velocity profile along the pipe, with flow external to the tool joint; $\theta c=90^{\circ} / \theta e=90^{\circ}$; BACAT fluid.

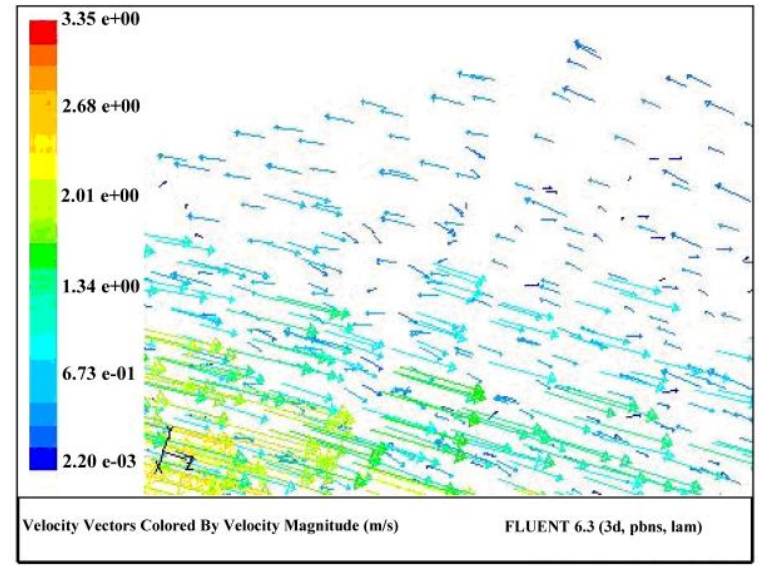

Figure 8. Representation of flow in the expansion zone; internal tool joint with $\theta c=18^{\circ} / \theta e=35^{\circ}$; BACAT fluid.

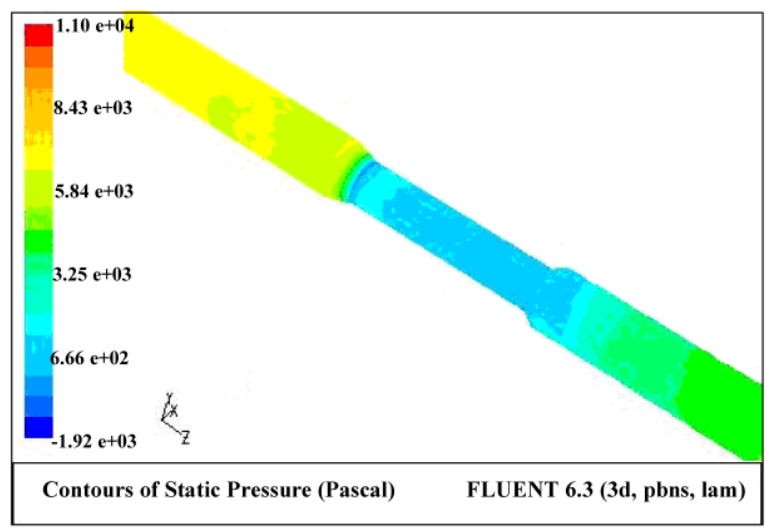

Figure 9. Pressure drop along the tool joint, internal flow configuration of the tool joint with $\theta c=18^{\circ} / \theta e=$ $35^{\circ}$, and BACAT fluid.
However, due to the low magnitude of the velocity oscillations this region was considered stable. Therefore, the ranges of $0.5 \mathrm{~m}$ before and after the accessory were sufficient to fully establish the fluid velocity profile. These ranges were used to build up the pilot flow loop.

Figure 8 shows that, from the initial position of the tool joint, the fluid undergoes an acceleration which causes instability of the velocity after the expansion passage. This was found by analyzing the velocity profiles, and was caused by the high recirculation of fluid in this region, i.e., no flow occurred in the opposite direction. The same behavior is observed in settings of both internal and external flow.

In Figure 8 the flow direction is represented by the vectors of greater magnitude (with green, yellow and light blue). However, there are vectors of smaller magnitude, shown in dark blue, against the main direction of flow, characterizing the recirculation region. Mendes et al. (2007) observed this behavior in viscoplastic fluid flow in regions of abrupt contraction followed by expansion.

In Figure 9, one can observe the effect, more pronounced in the entry and exit regions, of the presence of a recirculation region causing a pressure drop.

Table 2 shows a comparison between experimental and simulated pressure drop data for two drilling fluids. These deviations are due to uncertainties in obtaining the rheological data. The power-law model was used for modeling the rheology of the fluids.

Figure 10 shows a typical comparison between experimental and simulated data of pressure drop. The uncertainties were calculated using the deviations presented in Table 1. It is observed that simulation results are in agreement with experimental data if one considers the experimental uncertainty. It can be seen in Figure 10 that the uncertainties in the calculation of pressure drop are not symmetrical. That happens due to the nonlinearity of the equations describing the fluid flow. Simões (2005) obtained simulation results qualitatively that are similar to those presented in this work. The author did not present experimental data. However, the values obtained in the simulations were used to correlate the pressure drop data with Reynolds number. 
Table 2. Operational conditions for CFD simulations and results.

\begin{tabular}{|c|c|c|c|c|c|}
\hline Fluid & Accessory & $\begin{array}{c}\mathrm{v} \\
(\mathrm{m} / \mathrm{s})\end{array}$ & $\begin{array}{l}\Delta \mathrm{P}_{\exp } \\
(\mathrm{Pa})\end{array}$ & $\begin{array}{l}\Delta \mathrm{P}_{\mathrm{sim}} \\
(\mathrm{Pa})\end{array}$ & $\begin{array}{c}\text { Error } \\
(\%)\end{array}$ \\
\hline \multirow{4}{*}{ 宓 } & TJ Internal & 1.63 & 9,980 & 11,709 & -17 \\
\hline & $(\mathrm{DITJ}=15.24 \mathrm{~mm})$ & 0.79 & 6,683 & 6,983 & -4 \\
\hline & TJ external & 1.62 & 11,552 & 10,869 & 5 \\
\hline & $\left(\theta \mathrm{c}=18^{\circ} / \theta \mathrm{e}=35^{\circ}\right)$ & 1.06 & 9,613 & 9,262 & 3 \\
\hline \multirow{4}{*}{ 网 } & TJ internal & 0.65 & 4,577 & 4,309 & 5 \\
\hline & $(\mathrm{DITJ}=15.24 \mathrm{~mm})$ & 1.71 & 12,384 & 13,300 & -7 \\
\hline & TJ external & 1.65 & 9,143 & 9,993 & -9 \\
\hline & $\left(\theta \mathrm{c}=18^{\circ} / \theta \mathrm{e}=35^{\circ}\right)$ & 1.17 & 7,036 & 8,354 & -18 \\
\hline
\end{tabular}

\subsection{Evaluation of the correlation of pressure drop in tool joints}

Another way to calculate pressure drop in tool joints is to use correlations. In this way, Petrobras has been using a code that involves correlations described by Equations 8 to 18. After some tests, one can conclude that two parameters used in these correlations needed to be re-estimated, namely, Parameter $B$ in Equation 11, and Parameter $A$ in Equations 13 and 16.

Parameter evaluations were done using experimental data obtained with pure water and the fluids named BAC and BACAT in a code based on the maximum likelihood principle. The following results were obtained; $A=0.225 \pm 0.002$ and $B=$ $0.38 \pm 0.03$. For the external configuration, one can observe that the deviations were low in laminar regime, but higher in turbulent regime.
In Figures 11 and 12, typical results using old and new parameters obtained by correlations for internal and external flow are shown, respectively. The results demonstrate that Parameters $A$ and $B$ need to be re-estimated. For internal configuration (Figure 12), the correlations results are a better fit to the experimental data.

\subsection{Evaluation of the new parameters for an independent drill fluid}

This work presented data for such fluids as pure water, BAC, BACAT, and BAS. The authors assumed that the correlations presented do not depend on the studied fluids. Hence, they used pure water, BAC, and BACAT for parameter evaluation. Fluid BAS was used to validate the predictive quality of the correlations with new parameters.

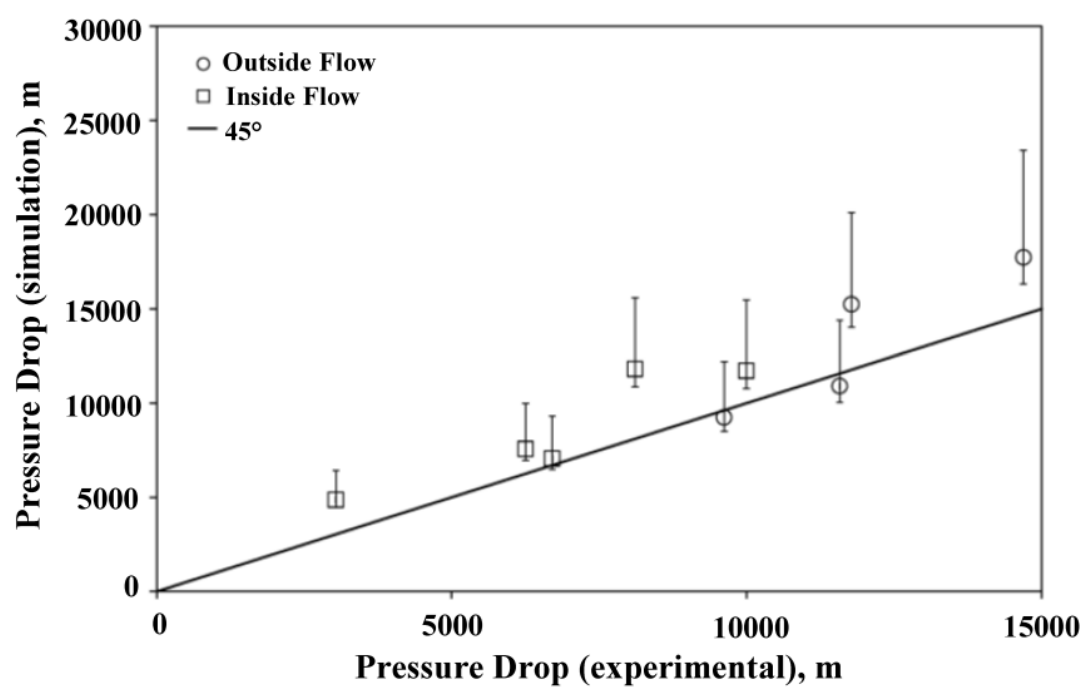

Figure 10. Influence of rheological parameters uncertainties in the pressure drop in simulations data for BACAT fluid flow in tool joints. 


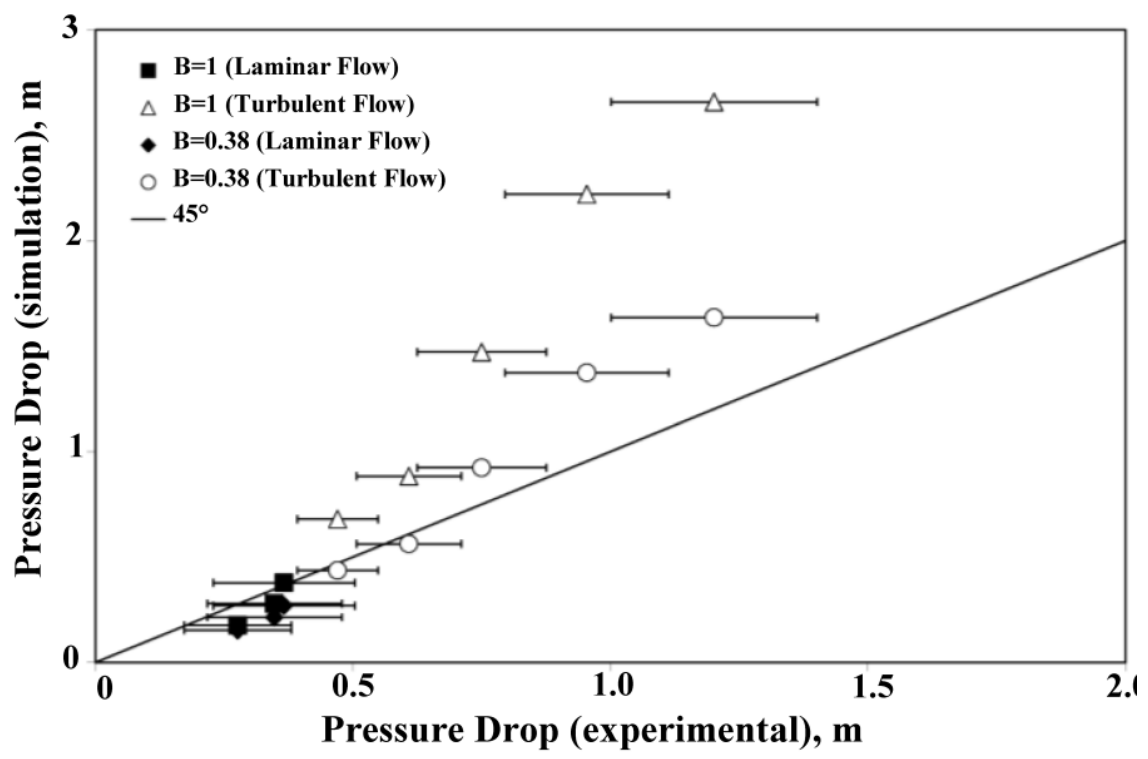

Figure 11. Experimental and calculated pressure drop in the external configuration of tool joint (BACAT fluid).

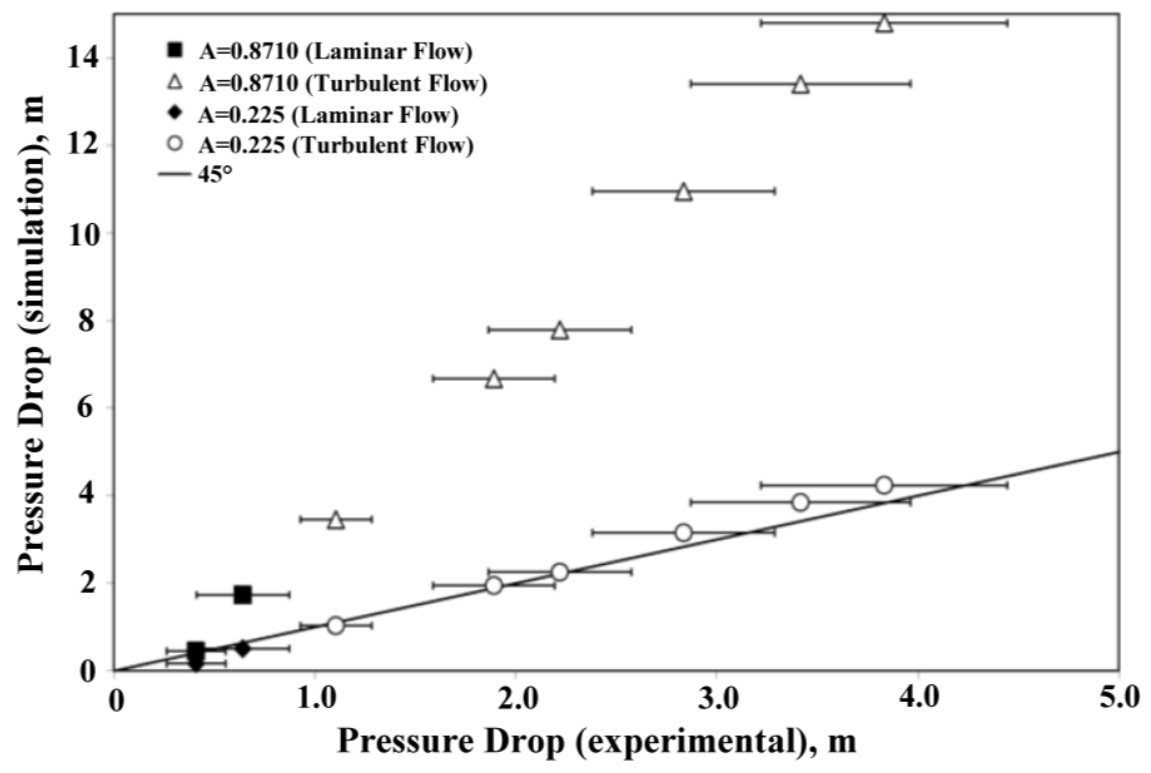

Figure 12. Experimental and calculated pressure drop in the internal configuration of tool joint (BACAT fluid).

Figures 13 and 14 show typical pressure drop data obtained experimentally and using the literature's correlations for the flow of BAS fluid, where $A=0.225$ and $B=0.38$. It is important to highlight that these data were not used in parameter estimation. Similar results were obtained for the other tool joints studied with different geometries. This evidence shows that the new estimated parameters provide more representative values for the tool joint configurations studied in this work. 


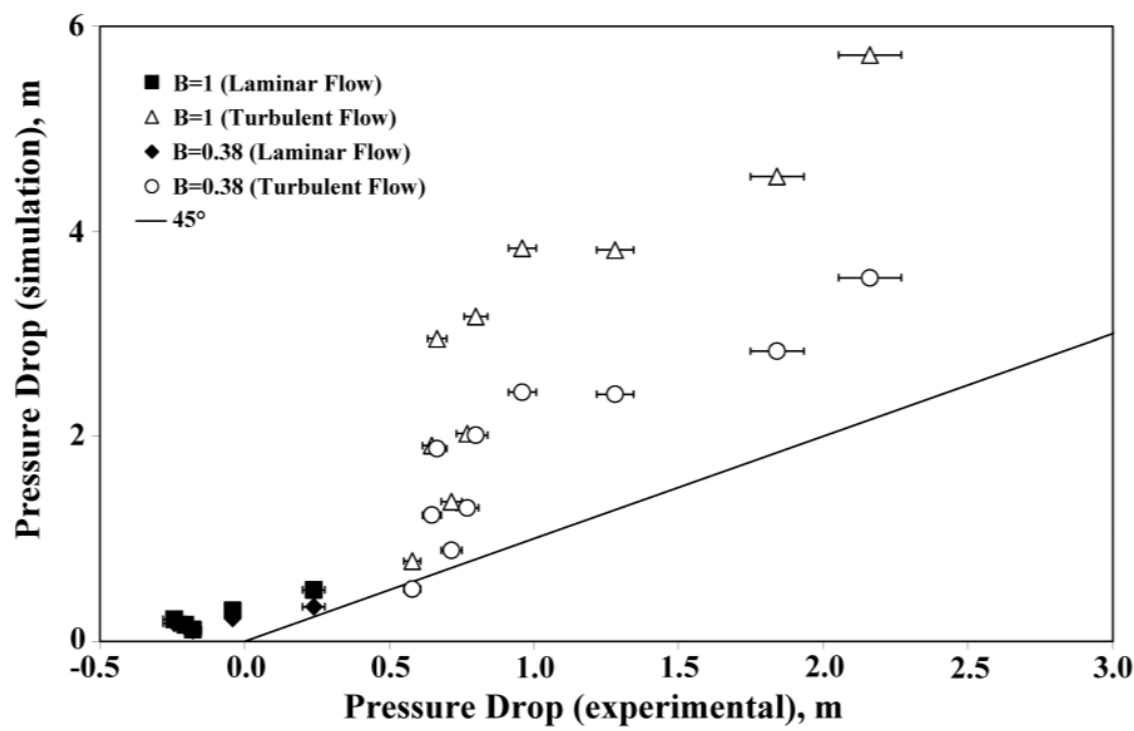

Figure 13. Experimental and calculated pressure drop in the external configuration of tool joints (BAS fluid).

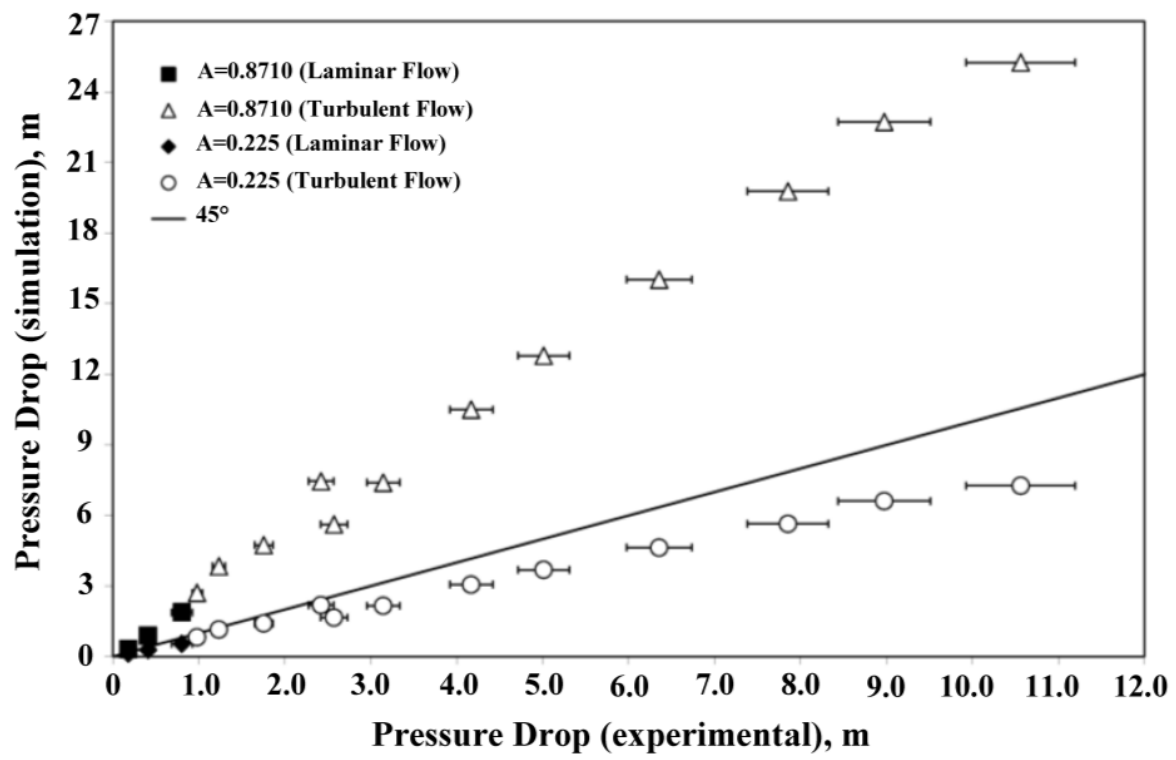

Figure 14. Experimental and calculated pressure drop in the internal configuration of tool joints (BAS fluid).

In general, for internal flow, the correlations and experimental data showed slight deviations. For external flow, the deviations were still higher in turbulent regime, although they have been satisfactory in the region of laminar flow.

\section{CONCLUSIONS}

The CFD simulations showed that the spacing of $0.5 \mathrm{~m}$ before and after the tool joints was sufficient to avoid the disturbances in pressure drop measurements. Qualitatively, the pressure and velocity profiles obtained by simulation using CFD 
packages were in agreement with literature. However, in some cases, there were significant deviations between experimental and simulated data. It was observed that one of the sources of these deviations is the uncertainties in the rheological data.

Pressure drop data in tool joints for waterbased muds with non-Newtonian behavior were taken to evaluate the literature's correlations for calculation of friction factors. It was necessary to re-estimate some parameters of the pressure drop correlations. After doing so, a good agreement was found between pressure drops calculated using correlations and CFD simulation data.

The coefficients $K_{c}$ and $K_{e}$ represent the pressure losses due to the sudden contraction and expansion of the flow entering and leaving the tool joints. For calculation of the pressures drop coefficients presented in this work, the parameters $A$, in Equations 13 and 16, and $B$ in Equation 11 need to be re-estimated. In general, with the new parameters, for internal flow, the correlations and experimental data showed slight deviations. For external flow, the deviations were higher in turbulent regime, although they have been satisfactory in the region of laminar flow.

\section{NOMENCLATURE}

A Parameter of Equations 13 and 16 (dimensionless)

B Parameter of Equation 11 (dimensionless)

CFD Computational Fluid Dynamics

D Diameter $(\mathrm{m})$

$D_{1}^{P} \quad$ Inner diameter $(m)$

$D_{0}{ }^{p} \quad$ Outer tube diameter $(m)$

$D_{1}^{T J} \quad$ Inner diameter of the tool joint $(m)$

$D_{O}{ }^{T J} \quad$ Outside diameter of tool joint $(m)$

$D_{H} \quad$ Hydraulic diameter $(m)$

$D_{1} \quad$ Outer diameter of inner tube $(m)$

$D_{2} \quad$ Inner diameter of the outer tube $(m)$

$f \quad$ Friction factor (dimensionless.)

$\mathrm{F}_{\mathrm{c}} \quad$ Pressure drop in the region of contraction $\left(\mathrm{m}^{2} \cdot \mathrm{s}^{-2}\right)$

$\mathrm{F}_{\mathrm{e}} \quad$ Pressure drop in the new expansion $\left(\mathrm{m}^{2} \cdot \mathrm{s}^{-2}\right)$

$k \quad$ Parameter of the power-law model ( $\left.\mathrm{Pa} . \mathrm{s}^{\mathrm{n}}\right)$

$\mathrm{K} \quad$ Pressure drop coefficient (dimensionless)

$\mathrm{K}_{\mathrm{e}} \quad$ Coefficient of pressure loss in the expansion region (dimensionless)
$\mathrm{K}_{\mathrm{c}} \quad$ Coefficient of pressure loss in the region of contraction (dimensionless)

$\mathrm{K}_{1} \quad$ Parameter of Equation 13 (dimensionless)

$\mathrm{K}_{2} \quad$ Parameter of Equation 16 (dimensionless)

$L \quad$ Length of the straight section $(\mathrm{m})$

$\mathrm{L}_{c} \quad$ Length of the contraction region $(\mathrm{m})$

$\mathrm{L}_{\mathrm{e}} \quad$ Length of the expansion region $(\mathrm{m})$

$\mathrm{n} \quad$ Parameter of the power-law model (dimensionless)

Q Volumetric flow rate $\left(\mathrm{m}^{3} / \mathrm{s}\right)$

$r \quad$ Radial coordinate (dimensionless)

$\mathrm{R}^{2} \quad$ Correlation coefficient (dimensionless)

Re Generalized Reynolds number - power law model (dimensionless)

$v \quad$ Average fluid velocity $(\mathrm{m} / \mathrm{s})$

$v_{r} \quad$ Velocity in the radial direction $(\mathrm{m} / \mathrm{s})$

$v_{\theta} \quad$ Velocity in tangential direction $(\mathrm{m} / \mathrm{s})$

$v_{z} \quad$ Velocity in the axial direction $(\mathrm{m} / \mathrm{s})$

$\mathrm{x}_{c} \quad$ Parameter of Equation 14 (dimensionless)

$\mathrm{x}_{\mathrm{e}} \quad$ Parameter equation 17 (dimensionless)

$r \quad$ Radial coordinate (dimensionless)

z Axial coordinate (dimensionless)

\section{Greek Letters}

$\beta \quad$ Ratio between internal and external radii, $D_{0}{ }^{T J} / D_{1}{ }^{P}$, see figure 2-(a),(dimensionless)

$\lambda \quad$ Shear rate $\left(\mathrm{s}^{-1}\right)$

$\mu \quad$ Effective viscosity $\left(\mathrm{Kg} \cdot \mathrm{m}^{-1} \cdot \mathrm{s}^{-1}\right)$

$\theta \quad$ Tangential coordinate (dimensionless)

$\theta_{c} \quad$ Angle in the contraction region (degrees)

$\theta_{\mathrm{e}} \quad$ Angle in the expansion region (degrees)

$\rho \quad$ Density of the fluid $\left(\mathrm{Kg} \cdot \mathrm{m}^{-3}\right)$

$\sigma \quad$ Standard deviation (dimensionless)

$\tau \quad$ Shear stress $(\mathrm{Pa})$

$\triangle \mathrm{P} \quad$ Pressure Drop ( $\mathrm{Pa})$

$\Delta \mathrm{P}_{\mathrm{e}} \quad$ Pressure drop of the region expansion ( $\left.\mathrm{Pa}\right)$

$\Delta \mathrm{P}_{\mathrm{c}} \quad$ Pressure drop in the region of contraction (Pa)

$\Delta \mathrm{P}_{\text {exp }} \quad$ Experimental pressure drop $(\mathrm{Pa})$

$\Delta \mathrm{P}_{\text {sim }} \quad$ Simulated pressure drop $(\mathrm{Pa})$

$\Delta \mathrm{P}_{\text {calc }}$ Pressure drop calculated by correlation $(\mathrm{Pa})$

\section{ACKNOWLEDGMENTS}

The authors gratefully acknowledge the financial support provided by PETROBRAS, FINEP, CNPq and CAPES. 


\section{REFERENCES}

Bird, R. B.; Stewart, W. E.; Lightffot, E. N. Transport Phenomena. New York: John Willey \& Sons Inc., $2^{\text {nd }}$ Edition, 2001.

Bourgoyne, A. T.; Milheim, K. K.; Chenevert, M. E.; Young, F. S. Applied Drilling Engineering. Texas: SPE, Richardson, $2^{\text {nd }}$ Edition, 1991.

Fox, R. W.; McDonald, A. T.; Pritchard, P. J. Introduction to Fluid Mechanics. New York: John Wiley \& Sons Inc., $6^{\text {th }}$ Edition, 2004.

Gomes, F. J. A. D. Hydraulic, fluid power: rationalization of the friction factor. In: First Technical Meeting on Information Technology in Drilling, CAPER/87, Model 7, Salvador, Brazil, 1987.

Himmelblau, D. M. Process Analysis by Statistical Methods. New York: John Wiley \& Sons, Inc., 1970.

Jeong, Y.; Shah, S. Analysis of tool joint effects for accurate friction pressure loss calculations. In: IADC/SPE Drilling Conference, Paper SPE 87182MS, Dallas, Texas, 2004. http://dx.doi.org/10.2118/87182-MS
McCain, R. C. Pressure Loss in Tool Joint. Texas: Mobil, Dallas, 1994.

Mendes, P. R. S.; Naccache, M. F.; Varges, P. R.; Marchesini, F. H. Flow of viscoplastic liquids through axisymmetric expansions - contractions. Journal of non-Newtonian Fluid Mechanics, v.142, p. 207-217, 2007.

http://dx.doi.org/10.1016/i.jnnfm.2006.09.007

Metzner, A. B.; Reed, J. C. Flow of nonNewtonian fluids-correlation of laminar, transition, and turbulent flow regions. AICHE Journal, v.1, p.434-440, 1955.

http://dx.doi.org/10.1002/aic.690010409

Scheid, C. M.; Calçada, L. A.; Braga, E. R.; Paraiso, E. C. H.; Martins, A. L. Hydraulic study of drilling fluid flow in circular and annular tubes. Brazilian Journal of Petroleum and Gas, v.5, n.4, p.230-253, 2011. http://dx.doi.org/10.5419/bjpg2011$\underline{0023}$

Simões, S. Q. The effect of tool joints on ECD while drilling with power law fluids. Master's Dissertation, University of Tulsa, Oklahoma, USA, 2005. 